\title{
Product portfolio management and performance: Evidence from a survey of innovative Brazilian companies is
}

\author{
Daniel Jugend ${ }^{\text {a,* }}$, Sérgio Luis da Silva ${ }^{\mathrm{b}}$, Manoel Henrique Salgado ${ }^{\text {a }}$, Paulo Augusto Cauchick Miguel ${ }^{\mathrm{c}}$ \\ a São Paulo State University UNESP, Av. Engenheiro Luiz Edmundo Carrijo Coube 14-01, PO BOX 17033-360, Bauru, SP, Brazil \\ ${ }^{\mathrm{b}}$ Federal University of São Carlos UFSCar, Rodovia Washington Luís, km 235 - SP-310, PO BOX 13565-905, São Carlos, SP, Brazil \\ c Federal University of Santa Catarina, UFSC, Campus Universitário Trindade, PO BOX 476, 88040-900 Florianópolis, SC, Brazil
}

\section{A R T I C L E I N F O}

Article history:

Received 1 January 2016

Received in revised form 1 March 2016

Accepted 1 April 2016

Available online 2 May 2016

\section{Keywords:}

Innovation management

New product development

Product portfolio management

Performance objectives

\begin{abstract}
A B S T R A C T
Portfolio management is gaining increasing attention from researchers and practitioners involved in innovation and product development. In this context, this study aims to analyze the product portfolio management practices that innovative firms in a developing country adopt. This investigation also aims to establish the relationship between these practices and product portfolio performance. The study carries out a quantitative survey on a sample of 71 Brazilian firms, and the results demonstrate that practices associated with formalization, systematization, and clarification in product portfolio decision making significantly influence the fulfillment of performance objectives. In addition, some companies face difficulty in fulfilling the balance of portfolio products, and this difficulty possibly relates to the concentration of incremental innovation efforts in new product development.
\end{abstract}

(c) 2016 Elsevier Inc. All rights reserved.

\section{Introduction}

By determining the current and future set of products that a company uses to compete in the market, product portfolio management (PPM) is gaining increasing attention from researchers and professionals involved in innovation and product development (Kester, Hultink, \& Griffin, 2014; McNally, Durmuşoğlu, \& Calantone, 2013). Product portfolio decisions fundamentally fall into the following categories (Cooper, Edgett, \& Kleinschmidt, 1999): selection and prioritization of the group of product projects that make the implementation of the business strategy viable, decisions about the allocation of resources, and investments in the different product projects through time.

Decision making regarding product portfolios is complex because, in addition to being part of the planning stages of new product development (NPD) (Heising, 2012), such decision making also relates to political values and a company's power (Kester, Griffin, Hultink, \& Lauche, 2011; Martinsuo, 2013). This tendency creates a challenge for the search for balance (i.e., an ideal mix of products in the company's portfolio), which must take into consideration the various interests of the stakeholders. If the company is unable to make effective decisions, the firm may compromise its portfolio and consequently, its NPD performance.

\footnotetext{
* The authors would like to thank the FAPESP (São Paulo Research Foundation) fo financially supporting this study (Project no. 11/51596-5), and to the anonymous reviewers for their valuable comments.

* Corresponding author.

E-mail addresses: daniel@feb.unesp.br (D. Jugend), sergiol@ufscar.br (S.L. da Silva), henri@feb.unesp.br (M.H. Salgado), paulo.cauchick@ufsc.br (P.A.C. Miguel).
}

In the last few decades, researchers have been conducting various studies with the objective of improving product portfolio performance. These studies recommend the adoption of specific management practices, such as financial and scoring tools decision making by multifunctional teams, and systematization and formalization of such teams' activities (e.g. Kahn, Barczak, \& Moss, 2006; Kopmann, Kock, Killen, \& Gemünden, 2015). This present work aims to contribute to the PPM theory by analyzing the portfolio management practices in companies that operate in Brazil. The objective of the study is to establish the relationship between these practices and product portfolio performance. An assessment of the literature shows that a research gap exists in the relationships between the influences of PPM methods, the systematization and formalization of PPM, and the functional integration with product portfolio performance. The study performs a survey on a sample of 71 companies with innovative characteristics in the electronics and computer (hardware and software) sectors.

Many studies investigate the aspects of PPM in North American (Cooper et al., 1999; McNally et al., 2013), Australian (Killen, Hunt, \& Kleinschmidt, 2008), Asian (Oh, Yang, \& Lee, 2012), and European (Kock, Heising, \& Gemünden, 2015; Teller, Unger, Kock, \& Gemünden, 2012) firms. Despite the new attention Brazil receives for its economic contributions as a member of the BRIC (Brazil, Russia, India, China and South Africa) group of countries, few studies demonstrate the realities of companies that operate in the country with regard to PPM.

The next section, Section 2, defines the theoretical aspects this research investigates, in addition to the hypotheses the research uses for the fieldwork. Section 3 describes the study's research methods and the results from the survey responses. The last section, Section 4, 
presents the study's conclusions and discusses the findings' managerial implications, the study's limitations, and the directions for further work.

\section{Theoretical background and research hypotheses}

As a field of knowledge, PPM aims to support companies with regard to making a business strategy viable, optimizing resources, minimizing risks, and reducing the time to market in NPD (Cooper et al., 1999; Jacobs \& Swink, 2011). In a practical situation, portfolio management can help in making decisions about prioritizing resources and allocating them to the most promising product projects, while at the same time avoiding the waste of such resources.

PPM aims to attain three principal performance objectives (Cooper et al., 1999; Cooper, Edgett, \& Kleinschmidt, 2000):

(i) Strategic alignment: The translation and coordination of the company strategy for a group of products in a way that considers the current or future product lines that will be responsible for making the business strategy viable;

(ii) Balance: The establishment of the mix of product projects, considering aspects such as the level of innovation of each of the products in the portfolio (radical and incremental innovation projects), the expected risks and rewards associated with the development of these projects, the target market segments of each product, and the diversification of the portfolio with regard to product development times;

(iii) Maximized portfolio value: The optimization of the relationship between the resources used in and the expected returns from the product projects.

Various researchers who work on PPM emphasize the importance of fulfilling these three performance objectives (e.g. Jugend \& da Silva, 2014; Killen et al., 2008; McNally et al., 2013; Meskendahl, 2010; Mikkola, 2001; Oh et al., 2012; Perks, 2007). Given these strategic and simultaneously complex characteristics, various studies recommend the adoption of specific formalized and objective practices to support PPM activities. This study categorizes these PPM activities into (i) methods (e.g., Dutra, Ribeiro, \& de Carvalho, 2014), (ii) formalization (e.g., Teller et al., 2012), and (iii) integration (e.g. Kester et al., 2011; Perks, 2007).

Researchers recommend different management practices and specific methods to obtain adequate product portfolio performance. The application of these methods to PPM is useful for evaluating strategic, market, technological, and risk factors, as well as the return on investment from the product portfolio (Coulon, Ernst, Lichtenthaler, \& Vollmoeller, 2009). The PPM literature cites the following methods (Jugend \& da Silva, 2014): financial methods (Archer \& Ghasemzadeh, 1999; Chao \& Kavadias, 2008; Killen et al., 2008), marketing and market research information (Abrantes \& Figueiredo, 2014; Kester et al., 2011), scoring and ranking (Bitman \& Sharif, 2008; Henriksen \& Traynor, 1999), checklists (Christiansen \& Varnes, 2008), maps (Closs, Jacobs, Swink, \& Webb, 2008; Oliveira \& Rozenfeld, 2010), and graphs and diagrams (Mikkola, 2001; Oh et al., 2012).

Therefore, the study expects to find a positive relationship between portfolio management methods and the fulfillment of performance objectives, and accordingly, establishes the following hypothesis:

H1. A positive correlation exists between PPM methods and the fulfillment of product portfolio performance objectives.

Cooper et al. (1999); Kahn et al. (2006), and Teller et al. (2012) argue that the formalization of PPM, in combination with support from senior management, increases the companies' maturity in terms of their portfolio management activities (Kopmann et al., 2015). This formalization aims to clarify the rules, procedures, and criteria for the analysis and decision making for all products in the portfolio (Archer \& Ghasemzadeh, 1999; Meskendahl, 2010). Therefore, the study expects to find a positive relationship between the formalization of PPM and fulfillment of the portfolio objectives, and accordingly, establishes the following second hypothesis:

H2. A positive correlation between the level of formalization of the product portfolio and the fulfillment of the portfolio performance objectives.

PPM methods (e.g., financial methods, scoring, ranking, checklists, maps, and graphs and diagrams) tend to contribute to the systematization of portfolio decision making and, consequently, helps improve this process (Cooper et al., 1999; Coulon et al., 2009; McNally et al., 2013). As a result, a positive relationship between management methods and the formalization of PPM may exist, as the next hypothesis proposes:

H3. A positive correlation exists between PPM methods and the formalization of a product portfolio.

Some studies (e.g. Kester et al., 2011; Perks, 2007; Weissenberger-Eibl \& Teufel, 2011) consider functional integration as a best practice for PPM. Integration promotes effective decision making for the product portfolio because it strengthens the sharing of knowledge and information among the company's different functional perspectives, including in the evaluations of the technical, managerial, and market aspects involved with PPM (McNally, Durmuşoğlu, Calantone, \& Harmancioglu, 2009; Perks, 2007). Jacobs and Swink (2011) highlight that integrating the functions of marketing, engineering, R\&D, production, and sales is important to PPM. Heising (2012) also discusses integration, especially in the NPD planning phases, when the change and interruption costs are still very low in relation to the final stages of product development. Thus, the study expects to find a positive correlation between integration and the fulfillment of product portfolio performance objectives, as the fourth hypothesis states:

H4. A positive correlation exists between the integration of the functions involved in PPM and the fulfillment of the product portfolio performance objectives.

Section 3 establishes the research design based on this study's theoretical framework and research hypotheses derived from PPM theory. Fig. 1 illustrates the model that guides this study.

\section{Research design}

To achieve its objectives, the study conducts an exploratory quantitative investigation using a questionnaire based on the study's research framework (see Fig. 1). Appendix 1 lists the factors and variables in the survey, as well as the underpinning works. The appendix also includes the mean and standard deviation results for each examined variable.

The study gathers the data using the structured questionnaire. The questionnaire includes several statements based on the four research hypotheses and asks respondents to indicate their agreement or disagreement with a statement on a five-point Likert scale (from $1=$ 'totally disagree' to $5=$ 'totally agree'). Before the study finalizes the structure of the survey instrument, it conducts a pilot test of the questionnaire with a PPM expert in academia and an executive at a company in the electronics sector.

The study conducts the survey on a sample of companies in the electronics and computer sectors. A recent report on innovation by the Brazilian Institute for Geography and Statistics (mostly known in Portuguese by the acronym IBGE) (IBGE, 2013) provides support for the study's choice of sectors. These sectors have some of the highest rates of innovation in Brazil. The electronics and computer sectors invest $13.5 \%$ and $6.5 \%$, respectively, of their revenue in innovation (IBGE, 2013). Companies in these sectors continuously develop new products 


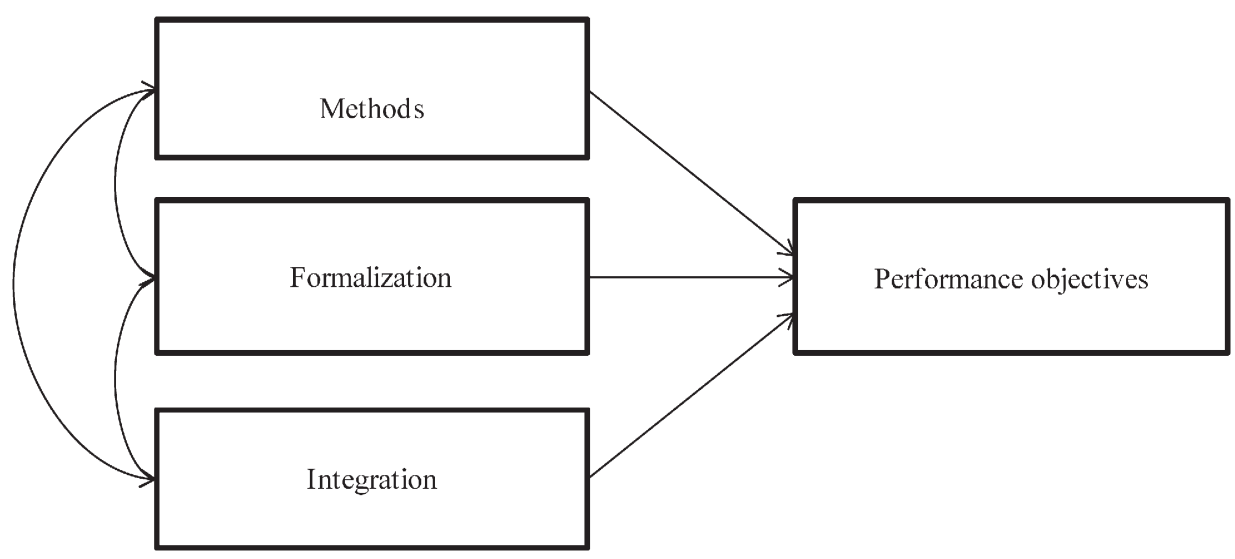

Fig. 1. Research model.

and are among the best in the country owing to their innovation, and thus, are ideal for an investigation concerning PPM.

To identify the population of interest, the study initially considers the database of the Brazilian Electrical and Electronics Industry Association (mostly known in Portuguese by the acronym ABINEE) and the companies registered with the National Institute of Metrology, Quality, and Technology (mostly known in Portuguese by the acronym INMETRO). These institutions are corporate and governmental, respectively, and are representative of the sectors surveyed in the country. The study identifies 496 companies and invites them by email to participate in the research.

The study also creates a website to house the research instrument and to record the companies' details and send each of them a link to the questionnaire. Upon receipt, the link directs the respondent to the questionnaire that the website. Seventy-nine companies fill out the questionnaires, but eight of those companies do not meet the survey objectives, and thus, the study excludes their questionnaires from the analysis. The final sample includes 71 companies, resulting in a response rate of $14.4 \%$, which operations management research may consider adequate (Synodinos, 2003).

Of these 71 companies, $43.7 \%$ are small, $40.8 \%$ are medium, and $15.5 \%$ are large. To define the size of the companies, the study considers the criteria of the Brazilian Micro and Small Business Support Service (mostly known in Portuguese by the acronym SEBRAE) and the IBGE. The study defines small companies as those with 20 to 99 employees, medium companies as those with 100 to 499 employees, and large companies as those with over 500 employees. The vast majority of respondents (90.1\%) occupy the following positions in their firms: directors, managers, owners, and engineers. Finally, $86 \%$ of the respondent companies are in the electronics sector and the rest in the computer sector.

In order to analyze the relationship between PPM methods, formalization, integration, and the fulfillment of product portfolio performance objectives (see Fig. 2), the study uses a regression model (Maroco, 2010), along with the SPSS software. The study also uses a significance level of $5 \%$ for all the regression analysis results.

\section{Research results}

The study initially proposes a descriptive display only considering the mean and standard deviation of each variable (see Appendix 1). Table 1 compares the factors the study investigates, considering the sizes of the companies. The study uses the non-parametric Kruskal-Wallis test to compare the variables (Siegel \& Castellan, 2006).

As can be seen in Table 1, integration is the only factor that shows a significant statistical difference when considering company size. This result indicates that the size of the company influences its integration practices and that large companies make a greater effort to integrate the different departments involved with PPM, owing to the greater resources these organizations have.

Although not statistically significant, some of the results Table 1 presents (including management methods) suggest that large companies apply these procedures more intensely than small and medium companies. The study also observes a similar behavior among the companies with regard to formalization. Even with a higher score in terms of the integration and application of management methods, large companies demonstrate greater difficulties in fulfilling the product

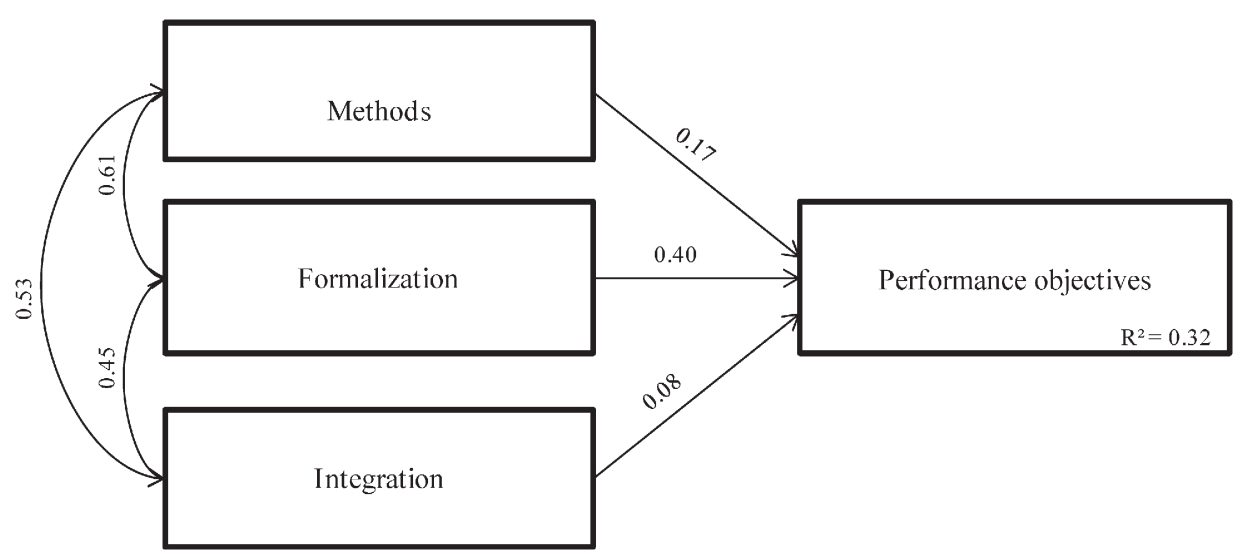

Fig. 2. Regression results (with standardized estimates of model coefficients and correlation values, p-value $=0.00001$ ). 
Table 1

Descriptive analysis considering company size.

\begin{tabular}{|c|c|c|c|c|c|c|c|}
\hline \multicolumn{8}{|l|}{ Company size } \\
\hline \multirow{2}{*}{ Factor } & \multicolumn{2}{|l|}{ Small } & \multicolumn{2}{|c|}{ Medium } & \multicolumn{2}{|l|}{ Large } & \multirow{2}{*}{$\frac{\text { Kruskal-Wallis test }}{\text { p-Value }}$} \\
\hline & Mean & St. dev & Mean & St. dev & Mean & St. dev & \\
\hline Methods & 2.87 & 0.86 & 2.84 & 0.73 & 3.21 & 0.99 & 0.255 \\
\hline Formalization & 3.08 & 0.91 & 3.03 & 1.00 & 3.43 & 1.38 & 0.455 \\
\hline Integration & 3.72 & 0.52 & 3.80 & 0.54 & 4.21 & 0.78 & 0.041 \\
\hline $\begin{array}{c}\text { Performance } \\
\text { objectives }\end{array}$ & 3.24 & 0.85 & 3.39 & 0.77 & 3.09 & 0.87 & 0.562 \\
\hline
\end{tabular}

portfolio performance objectives, albeit the differences are not statistically significant. Additionally, no statistically significant differences exist between the sectors, the study surveys (electronics and computers) and the fulfillment of the performance objectives $(p=0.36)$.

Fig. 2 presents the paths and results of the regression analysis of the factors the study investigates. All the factors have a level of reliability (Cronbach's alpha) greater than 0.70 , which can be considered satisfactory with regard to the internal consistency of the applied instrument (Hair, Black, Babin, Anderson, \& Tatham, 2006). The study uses the variance inflation factor (VIF) for the analysis of the multicollinearity of the independent factors, and all values are less than 2, which is satisfactory (Maroco, 2010).

The regression model of the product portfolio performance objectives according to PPM methods, integration, and formalization (see Fig. 2) highlights the significant influence of formalization. This result suggests that the definition of clear rules, adoption of standard criteria for project and product evaluation, and formalization and systematization of product portfolio decision making effectively contribute to the fulfillment of the product portfolio performance objectives. Nevertheless, the model also indicates that methods and integration have less influence on the achievement of performance objectives. Thus, all the three factors influence the portfolio performance, although most of this influence comes from the formalization factor.

Fig. 2 also shows a significant positive correlation between methods and formalization. This result suggests that the adoption of management methods may contribute to the formalization, systematization, and clarification of product portfolio decision making, and, consequently, may contribute to the maturity of the company's PPM. This positive correlation also occurs between methods and integration, and this result demonstrates that management methods, such as financial methods, scoring, ranking, and maps, contribute to the integration of the departments involved with PPM.

The results statistically confirm the four research hypotheses and demonstrate that the practices the study presents in the literature review section indeed contribute to the companies' product portfolio performance. However, interestingly, formalization has the greatest influence on the fulfillment of the performance objectives. In addition, the results of the correlations shown in Fig. 2 indicate that management methods promote not only the formalization of PPM, but also a greater integration between the different departments involved in PPM.

\section{Discussion of results}

This research demonstrates that formalization and systematization practices (Hauser, Tellis, \& Griffin, 2006; Kahn et al., 2006) contribute to the achievement of the product portfolio performance objectives. That is, efforts to create clear and explicit rules, procedures, and criteria that companies apply to analysis and decision making in product development significantly influence the achievement of the performance objectives.

In analyzing the correlations between the factors, the study also verifies that management methods traditionally recommended for product portfolio decision making, such as financial methods, scoring, ranking, checklists, and maps, contribute to greater functional integration in PPM. The results of this research also suggest that these management methods effectively promote the company's maturity in terms of its PPM and, consequently, the fulfillment of product portfolio performance objectives. While also acknowledging that some recent research indicates that product portfolio decision making should also be analyzed based on the informal and subjective mechanisms and negotiations within organizations (Martinsuo, 2013; Weissenberger-Eibl \& Teufel, 2011), the results of this study reinforce the importance of ensuring formal and rational PPM practices.

Among the management methods companies most frequently employ, this study highlights finance and market research. In this sense, the results of this study somewhat converge with those of Cooper et al. (2000) and Killen et al. (2008). Financial methods are some of the most commonly used methods because they are wellknown in both academia and practice, and thus, the study expects to find the significant influence of the use of financial variables, such as net present value, internal rate of return, and payback. This result, however, does not occur.

Among the methods that the companies in the sample apply, the study finds that the companies emphasize market research activities above others. This result indicates that companies are concerned about articulating PPM within their fundamental marketing activities. In addition to the basic importance of market research in identifying customer needs for product development, another reason for this result relates to the market in which the companies operate in Brazil. Because a large number of the companies operate in the business-to-business context (de Toledo, da Silva, de Paula, Mendes, \& Jugend, 2007), companies initiate many new projects for developing products when customers request such products.

This research verifies that overall, the companies' application of scoring, diagrams, and graphs is low. The study does not expect this result, as these methods are traditionally recommended and widely disseminated in the literature, including in management guidelines. Additionally, Cooper et al. (1999) and McNally et al. (2009) already demonstrate the frequent application of these methods among the companies they investigate.

A comparison of the results for the companies of different sizes shows that large companies demonstrate greater functional integration, employment of management methods, formalization, and systematization. This result confirms the study's expectation, since large companies in general have better-structured departments and dedicated managers.

The greatest difficulty that companies face in achieving balance in relation to strategic alignment and value maximization possibly relates to the concentration of efforts in the incremental development of products. This scenario is the most typical among Brazilian high-tech companies (de Toledo et al., 2007). One possible reason for this tendency is the companies' emphasis on the incremental innovation of products, resulting in an unbalanced portfolio with little focus on long-term, radical innovation, as other studies (e.g. Chao \& Kavadias, 2008; Kester et al., 2011) observe.

The managerial implications resulting from this research assert that the best product portfolio performance depends mostly on a higher level of objectivity in decision making, and this higher degree of objectivity comes from the formal and systematic application of the different PPM methods. Systematization can be based on existing models of portfolio management that propose the formalization of previously defined stages for NPD management. Take, for example, the "stagegates" that Cooper et al. $(1999,2000)$ propose. The different methods that the study investigates (financial methods, maps, scores, checklists, diagrams, and graphs) can be applied in PPM phases for the approval of ideas, and later, for the prioritization, freezing, or elimination of product projects.

Specifically for the investigated companies, greater dissemination and more effective implementation of the following PPM methods, which have low application, would be important: (i) scoring and 
prioritization models, which help the portfolio management team score, rank, and prioritize product projects according to their expected median of performance, and (ii) diagrams, such as the BCG (Boston Consulting Group) matrixes and GE (General Electric) bubble charts, which are useful for simultaneously analyzing the alignment between the product portfolio, company strategy, and balance.

\section{Conclusions}

By identifying and analyzing innovative Brazilian companies' PPM practices and such practices' relationships to the fulfillment of product portfolio performance objectives, this study contributes to the literature on innovation and NPD. Furthermore, the study adds to the various studies on this subject in North America, Europe, and Asia by analyzing the environments in these innovative companies operating in Brazil.

This research demonstrates the importance of formal methods of systematization to obtaining better product portfolio performance. Furthermore, the research finds that the company's greater maturity in terms of its PPM can be achieved through formal management methods specifically recommended for product portfolio decision making, such as for financial methods, scores, checklists, diagrams, and maps.

The acceptance of the study's four research hypotheses confirms that the PPM antecedents this study investigates (methods, formalization, and integration) contribute to a higher level of product portfolio performance. This finding suggests that the managers involved in decision making for product projects should know, disseminate, and apply these practices to NPD.

Among the main product portfolio performance objectives, companies face the greatest difficulty in attaining balance (i.e., an ideal mix of products in the company's portfolio). Owing to the quantitative characteristics of the research method this study employs, the study is unable to identify the reasons for such difficulty. However, this problem may be due to the low willingness of companies to develop projects for products containing radical innovation-products that, consequently, demand greater, riskier, and longer-term investments. Future in-depth case studies could explore this aspect in companies that face difficulty in attaining balance.

Finally, despite its contributions, this study has some limitations. The first limitation relates to the sample. Further work could gather data from more sectors, conduct exploratory factor analysis, and validate the results through a confirmatory factor analysis. Alternatively, future studies could consider creating a second-order model for structural equation modeling or partial least squares regression.

The present study also focuses on companies in the electronics and computer sectors, and studies that examine companies in other industries and sectors, such as those less focused on product technologies (e.g., food), may obtain results that are different from those of the present study. Additionally, this study emphasizes four factors for PPM analysis (methods, formalization, integration, and product portfolio performance). The current literature on portfolio management acknowledges the importance of other factors, such as the characteristics of leaders of new product projects and the importance that a company confers on PPM, and as such, recommends the investigation of these factors as well. Thus, future studies should not only replicate this research in different industries and sectors but also include other factors that affect portfolio performance and NPD. Future research could establish the relationships between the companies' PPM practices and the context of the Brazilian organizational culture. Cross-country comparison studies on PPM practices, as well as new directions for the establishment of good PPM practices are also other welcome possibilities for further research.
Appendix 1. Mean and standard deviation of the study variables.

\begin{tabular}{|c|c|c|c|}
\hline References & Variable & Mean & $\begin{array}{l}\text { St. } \\
\text { dev }\end{array}$ \\
\hline \multicolumn{4}{|c|}{ Factor: Management methods } \\
\hline & $\begin{array}{l}\text { The company uses financial methods } \\
\text { (e.g., payback, net present value, in- } \\
\text { ternal rate of return, equilibrium point, } \\
\text { and expected commercial value) in } \\
\text { product portfolio management (PPM). }\end{array}$ & 3.40 & 1.10 \\
\hline & $\begin{array}{l}\text { The company performs systematic and } \\
\text { formal market research that supports }\end{array}$ & 3.11 & 1.10 \\
\hline \multirow{5}{*}{$\begin{array}{l}\text { Based on Cooper et al. (1999) } \\
\text { and Jugend and da Silva } \\
\text { (2014) }\end{array}$} & PPM. & & \\
\hline & $\begin{array}{l}\text { The company uses product maps in } \\
\text { PPM. }\end{array}$ & 2.93 & 1.09 \\
\hline & $\begin{array}{l}\text { The company uses scoring models in } \\
\text { PPM. }\end{array}$ & 2.38 & 0.98 \\
\hline & $\begin{array}{l}\text { The company uses checklists in } \\
\text { product project analysis. }\end{array}$ & 3.06 & 1.17 \\
\hline & $\begin{array}{l}\text { The company uses diagrams and } \\
\text { graphs in PPM (e.g., BCG matrixes and } \\
\text { GE bubble charts). }\end{array}$ & 2.59 & 1.08 \\
\hline
\end{tabular}

Factor: Formalization

The company has well-established, explicit PPM methods.

$2.88 \quad 1.17$

In the evaluation of the PPM, the company applies the methods in a

$2.97 \quad 1.28$ standard manner, that is, similarly

Based on Kahn et al. (2006) for all projects.

The company's senior management $\quad 3.38 \quad 1.23$ definitively supports the PPM's

formal methods.

The company adopts clear methods $3.24 \quad 1.09$ to prioritize new product projects.

Factor: Integration

The senior management participates in PPM.

The marketing department participates in PPM.

The engineering and R\&D

$\begin{array}{ll}4.27 & 0.77\end{array}$

departments participate in PPM.

Based on Perks (2007), The production/manufacturing departments participate in PPM. The finance department participates in $3.31 \quad 0.98$ PPM.

The different departments involved with PPM have information about the clients' needs.

Factor: Performance objectives

Based on Cooper et al. (2000) Considering the available resources and McNally et al. (2013)

(time available resources the company is accustomed to developing an adequate number of new products.

The company's product portfolio has a balanced mix of projects (appropriate number of projects with varying degrees (i.e., high and low) of technological innovation and risk, as well as duration (i.e., short and long term), and market segments).

The resources allocated to the the strategic planning.

\section{References}

Abrantes, R., \& Figueiredo, J. (2014). Feature based process framework to manage scope in dynamic NPD portfolio. International Journal of Project Management, 32(5), 874-884. Archer, N. P., \& Ghasemzadeh, F. (1999). An integrated framework for project portfolio selection. International Journal of Project Management, 17(4), 207-216.

Bitman, W. R., \& Sharif, N. (2008). A conceptual framework for ranking R\&D projects. IEEE Transactions on Engineering Management, 55(2), 267-278. 
Chao, R. O., \& Kavadias, S. (2008). A theoretical framework for managing the new product development portfolio: When and how to use strategic buckets. Management Science, 54(5), 907-921.

Christiansen, J. K., \& Varnes, C. (2008). From models to practice: Decision making at portfolio meetings. International Journal of Quality \& Reliability Management, 25(1), 87-101.

Closs, D. J., Jacobs, M. A., Swink, M., \& Webb, G. S. (2008). Toward a theory of competencies for the management of product complexity: Six case studies. Journal of Operations Management, 26(5), 590-610.

Cooper, R. G., Edgett, S. J., \& Kleinschmidt, E. J. (1999). New product portfolio management: Practices and performance. Journal of Product Innovation Management, 16(4), 331-351.

Cooper, R. G., Edgett, S. J., \& Kleinschmidt, E. J. (2000). New problems, new solutions: Making portfolio management more effective. Research Technology Management, 43(2), 18-33.

Coulon, M., Ernst, H., Lichtenthaler, U., \& Vollmoeller, J. (2009). An overview of tools for managing the corporate innovation portfolio. International Journal of Technology Intelligence and Planning, 5(2), 221-239.

Dutra, C. C., Ribeiro, J. L. D., \& de Carvalho, M. M. (2014). An economic-probabilistic model for project selection and prioritization. International Journal of Project Management, 32(6), 1042-1055.

Hair, J. F., Jr., Black, W. C., Babin, B. J., Anderson, R. E., \& Tatham, R. L. (2006). Multivariate data analysis (6th ed.). Upper Saddle River, NJ: Prentice Hall.

Hauser, J., Tellis, G. J., \& Griffin, A. (2006). Research on innovation: A review agenda for marketing science. Marketing Science, 25(6), 687-717.

Heising, W. (2012). The integration of ideation and project portfolio management - A key factor for sustainable success. International Journal of Project Management, 30(5), 582-595.

Henriksen, A. D., \& Traynor, A. J. (1999). A practical R\&D project-selection scoring tool. IEEE Transactions on Engineering Management, 46(2), 158-170.

Ibge (2013). PINTEC - Technological National Research, Rio de Janeiro, 2013.

Jacobs, M. A., \& Swink, M. (2011). Product portfolio architectural complexity and operational performance: Incorporating the roles of learning and fixed assets. Journal of Operations Management, 29(7-8), 677-691.

Jugend, D., \& da Silva, S. L. (2014). Product-portfolio management: A framework based on methods, organization, and strategy. Concurrent Engineering: Research and Applications, 22(1), 17-28.

Kahn, K. B., Barczak, G., \& Moss, R. (2006). Perspective: Establishing an NPD best practices framework. Journal of Product Innovation Management, 23(2), 106-116.

Kester, L., Griffin, A., Hultink, E. J., \& Lauche, K. (2011). Exploring portfolio decision-making process. Journal of Product Innovation Management, 28(5), 641-661.

Kester, L., Hultink, E. J., \& Griffin, A. (2014). An empirical investigation of the antecedents and outcomes of NPD portfolio success. Journal of Product Innovation Management, 31(6), 1199-1213.

Killen, C. P., Hunt, R. A., \& Kleinschmidt, E. J. (2008). Project portfolio management for product innovation. International Journal of Quality \& Reliability Management, 25(1), 24-38.
Kock, A., Heising, W., \& Gemünden, H. G. (2015). How ideation portfolio management influences front-end success. Journal of Product Innovation Management, 32(4), 539-555.

Kopmann, J., Kock, A., Killen, C. P., \& Gemünden, H. G. (2015). Business case control in project portfolio-An empirical investigation of performance consequences and moderating effects. IEE Transactions on Engineering Management, 62(4), 529-543.

Maroco, J. (2010). Análise de equações estruturais: Fundamentos teóricos, softwares e aplicações. Pero Pinheiro: ReportNumber.

Martinsuo, M. (2013). Project portfolio management in practice and in context. International Journal of Project Management, 31(6), 794-803.

McNally, R. C., Durmuşoğlu, S. S., \& Calantone, R. J. (2013). New product portfolio management decisions: Antecedents and consequences. Journal of Product Innovation Management, 30(2), 245-261.

McNally, R. C., Durmuşoğlu, S. S., Calantone, R. J., \& Harmancioglu, N. (2009). Exploring new product portfolio management decisions: The role of managers' dispositional traits. Industrial Marketing Management, 38(1), 127-143.

Meskendahl, S. (2010). The influence of business strategy on project portfolio management and its success - A conceptual framework. International Journal of Project Management 28(8), 807-817.

Mikkola, J. H. (2001). Portfolio management of R\&D projects: Implications for innovation management. Technovation, 21(7), 423-435.

Oh, J., Yang, J., \& Lee, S. (2012). Managing uncertainty to improve decision-making in NPD portfolio management with a fuzzy expert system. Expert Systems with Application, 39(10), 9868-9885.

Oliveira, M. G., \& Rozenfeld, H. (2010). Integrating technology roadmapping and portfolio management at the front-end of new product development. Technological Forecasting and Social Change, 77(8), 1339-1354.

Perks, H. (2007). Inter-functional integration and industrial new product portfolio decision making: Exploring and articulating the linkages. Creativity and Innovation Management, 16(2), 152-164.

Siegel, S., \& Castellan, N. J., Jr. (2006). Estatística não-paramétrica para ciências do comportamento (2nd. ed.). Porto Alegre: Artmed (in Portuguese).

Synodinos, N. E. (2003). The "art" of questionnaire construction: Some important considerations for manufacturing studies. Integrated Manufacturing Systems, 14(3), 221-237.

Teller, J., Unger, B. N., Kock, A., \& Gemünden, H. G. (2012). Formalization of project portfolio management: The moderating role of project portfolio complexity. International Journal of Project Management, 30(5), 596-607.

de Toledo, J. C., da Silva, S. L., de Paula, S. M., Mendes, G. H. S., \& Jugend, D. (2007). Factors influencing new products success in small Brazilian medical and hospital equipment firms. In G. Loureiro, \& R. Curran (Eds.), Complex systems concurrent engineering: Collaboration, technology innovation and sustainability (pp. 657-664) (1st ed.). London: Springer-Verlag.

Weissenberger-Eibl, M. A., \& Teufel, B. (2011). Organizational politics in new product development project selection: A review of the current literature. European Journa of Innovation Management, 14(1), 51-73. 